\title{
PATTERN OF ANTI EPILEPTIC DRUG ADVERSE EFFECT IN TERTIARY REFERRAL HOSPITAL
}

\author{
Ria Damayanti ${ }^{1}$, Machlusil Husna ${ }^{1}$, Yeni Quinta Mondiani ${ }^{2}$, Shahdevi Nandar Kurniawan ${ }^{1}$ \\ Correspondence: dr.riadamayanti@ub.ac.id \\ ${ }^{1}$ Department of Neurology Faculty of Medicine Brawijaya University, Malang, Indonesia. \\ ${ }^{2}$ Resident in Department of Neurology Faculty of Medicine Brawijaya University, Malang, Indonesia.
}

\author{
Article History: \\ Received: June 8, 2020 \\ Accepted: June 15, 2020 \\ Published: July 1, 2020

\section{Cite this as:} \\ Damayanti R, Husna M, \\ Mondiani YQ, Kurniawan SN. \\ Pattern of anti epileptic drug \\ adverse effect in tertiary referral \\ hospital. Malang Neurology \\ Journal; 2020.6:77-81. \\ http://dx.doi.org/10.21776/ub.mnj \\ .2020.006.02.6
}

\begin{abstract}
Background: Epilepsy is a major chronic neurological problem in the world. The goal of epilepsy therapy is seizure-free and without side effects. The emergence of side effects in patients with epilepsy will be its limitations that can cause the failure of epilepsy therapy. Therefore, it is necessary to do a simple descriptive study, which illustrates the pattern of side effects of anti-epileptic drugs that occur in people with epilepsy, so that later clinicians are more alert and can take preventative measures.
\end{abstract}

Objective: Knowing the pattern of side effects of antiepileptic drugs at the Neurology Outpatient Clinic dr. Saiful Anwar hospital.

Methods: This research is an observational descriptive study. Samples were taken by filling the questionnaire at the Neurology Outpatient Clinic dr. Saiful Anwar hospital. Demographic data in this study will be presented in the frequency distribution table. Chi Square test is used to determine the relationship of demographic data, also the pattern of therapy with the side effects that arise.

Results: 93 epilepsy patients were involved in the study. More than $40 \%$ of patients experience side effects. The most common side effects appear in idiopathic epilepsy $(30.1 \%)$. Based on the duration of epilepsy, the most side effects appear in epilepsy duration> 10 years (17.2\%). However, from the results of the influence test using chi square, there was no significant difference between the duration of epilepsy with the appearance of side effects, even the type of epilepsy (p-value>0.05). 28 patients who experience side effects, appear after the duration of use of AED $1-5$ years. It was found that the duration of AED uses affected the emergence of side effects (p-value <0.05).

Conclusion: Side effects occur in patients taking anti-epileptic drugs, and are related to the duration of drug use. This data can be used to increase the awareness of clinicians related to the emergence of side effects in patients who consume AED.

Keywords: Epilepsy, antiepileptic drugs, side effects

\section{Introduction}

Epilepsy is still a major problem of all ages, throughout the world. WHO data in 2016, more than 50 million people in the world experience epilepsy, making it the main chronic neurological disease in the world. $70 \%$ of epilepsy patients can be said to recover from epilepsy (seizure free) if diagnosed and treated properly. ${ }^{1}$

The chronic course of epilepsy will be related to the length of use of pharmacotherapy, so doctors need to focus on the safety of the drug for patients. Various antiepileptic drugs were introduced in the last two decades, many patients did not respond to a single anti-epileptic drug. Some studies indicate the superiority of the combined use of the antiepileptic drug (AED) over monotherapy. ${ }^{2}$

On the other hand, the relationship between side effects in the field of neurology and epilepsy is not fully understood and it is difficult to know whether the side effects that arise are a consequence of epilepsy, reactions from epilepsy, or indeed side effects from treatment. Previously, data from cross-sectional studies showed that almost $80 \%$ of epilepsy sufferers taking anti-epileptic drugs had side effects. The emergence of side effects is also known as one of the causes of failure of epilepsy therapy. ${ }^{3,4}$

Therefore, research needs to be done about the side effects of the use of epilepsy drugs in the clinic of Dr. dr. Saiful Anwar Malang. The aim is to increase alertness and take preventative measures against side effects that arise in patients.

\section{Methods}

This research was an observational descriptive study to find out the pattern of side effects of anti epilepsy drugs in the neurological clinic of Dr. Saiful Anwar Malang.

\section{Research Samples}

The sample was in the form of a medical record from a questionnaire at the Neur Neurology Hospital Dr. Saiful Anwar Malang Indonesia in the period May 2017-July 2017 that met the inclusion criteria, namely patients who met the criteria for diagnosing epilepsy and had received antiepilepsy drug therapy for at least 3 months. 


\section{Research variable}

The independent variables were demographic data, namely age, gender, area of residence, education, duration of diagnosis of epilepsy, the form of seizure, cause of seizures, and pattern of therapy. The dependent variable in this study is the side effects that appear.

\section{Research procedure}

Data collection through interviews and questionnaires for the neurology outpatient clinic of Dr. Saiful Anwar Hospital Malang. Data was collected on the patient's identity in the form of age, sex, and social status of the patient, then implanted about the cause of the seizure, including from investigations, treatment history, and side effects that arise. Data is not always retrieved from one visit but can be completed in one or two subsequent visits.

\section{Data analysis}

Demographic data in this study will be presented in the frequency distribution table. Analysis of statistical data using the SPSS Statistics Subscription program. Chi Square test is used to determine the relationship of demographic data, also the pattern of therapy with the side effects that arise. Chi Square test results are expressed in $p$ values. If the value of $p<0.05$ then there is a significant relationship.

\section{Results}

\section{Patient Demographic Data}

Table 1. Patient Characteristics

\begin{tabular}{|c|c|c|c|}
\hline Variable & Category & $\begin{array}{c}\text { Frequency } \\
(\%) \\
\mathrm{N}=93\end{array}$ & $\begin{array}{c}\text { Percentage } \\
(\%)\end{array}$ \\
\hline \multirow[t]{3}{*}{ Age } & $<25$ & 34 & 36,5 \\
\hline & $25-50$ & 45 & 48,4 \\
\hline & $>50$ & 14 & 15,1 \\
\hline \multirow[t]{2}{*}{ Gender } & Man & 52 & 55,9 \\
\hline & Woman & 41 & 44,1 \\
\hline \multirow[t]{5}{*}{ Education } & Uneducated & 3 & 3,2 \\
\hline & Elementary school & 26 & 28 \\
\hline & Junior high school & 23 & 24,7 \\
\hline & Senior high school & 36 & 38,7 \\
\hline & Bachelor & 5 & 5,4 \\
\hline \multirow[t]{2}{*}{$\begin{array}{l}\text { Family } \\
\text { History }\end{array}$} & History (+) & 5 & 5,4 \\
\hline & History (-) & 88 & 94,6 \\
\hline \multirow[t]{3}{*}{$\begin{array}{l}\text { Seizure } \\
\text { type }\end{array}$} & General & 79 & 85 \\
\hline & Focal & 5 & 5,4 \\
\hline & Focal to bilateral & 9 & 9,6 \\
\hline \multirow[t]{8}{*}{ Cause } & Idiopatic & 63 & 67,7 \\
\hline & Symptomatic & & \\
\hline & - Trauma & 10 & 10.7 \\
\hline & - Stroke & 7 & 7.5 \\
\hline & - Infection & 5 & 5.4 \\
\hline & - Tumour & 5 & 5.4 \\
\hline & $\begin{array}{l}\text { - Vascular } \\
\text { malformation }\end{array}$ & 2 & 2.2 \\
\hline & - Metabolic & 1 & 1.1 \\
\hline
\end{tabular}

93 epilepsy patients were involved in the study. The majority of male patients were $55.9 \%$. With the majority> 50 people $(70 \%)$ patients come from the city of Malang. The educational status of the participants was mostly high school $(38.7 \%)$. More than $90 \%$ of patients, without a family history. $85 \%$ of patients (79 people) with a generalized form of seizures. Most $67.7 \%$ of patients, causal epilepsy is idiopathic. The duration of epilepsy was at most $>10$ years at $34.3 \%$, followed by $5-10$ years at $28 \%$. Complete demographic data can be seen in the table.

Relationship between Type and Duration of Epilepsy to Side Effects

Table 2. Side Effects of Specific Epilepsy Type and Duration

\begin{tabular}{llll}
\hline Variable & $\begin{array}{l}\text { Side Effect } \\
(+)(\%)\end{array}$ & $\begin{array}{l}\text { Side effect } \\
(-)(\boldsymbol{\%})\end{array}$ & p-value \\
\hline Cause & & & \\
- Idiopathic & $28(30,1 \%)$ & $33(35,5 \%)$ & $\mathbf{0 , 4 3 7}$ \\
- Symptomatic & $12(12,9 \%)$ & $20(21,5 \%)$ & \\
Duration of & & & \\
Epilepsy & & & \\
- < 3 years & $11(11,8 \%)$ & $6(6,5 \%)$ & $\mathbf{0 , 0 6 2}$ \\
- 3 - 5 years & $6(6,5 \%)$ & $12(12,9 \%)$ & \\
- 5-10 years & $7(7,5 \%)$ & $19(20,4 \%)$ & \\
- >10 years & $16(17,2 \%)$ & $16(17,2 \%)$ & \\
\hline
\end{tabular}

Based on table 2, it can be seen that the most side effects occur in idiopathic epilepsy $(30.1 \%)$. Where in the type of symptomatic epilepsy, fewer side effects occur (12.9\%). Based on the duration of epilepsy, the most side effects appear in epilepsy duration> 10 years (17.2\%). However, from the results of the influence test using chi square, there was no significant difference between the duration of epilepsy with the appearance of side effects, even the type of epilepsy (p-value> 0.05).

\section{Profile of Anti Epilepsy Drugs used}

Table 3. Types of Anti Epilepsy Drugs (AED)

\begin{tabular}{lcc}
\hline Drugs & Frequency & Percentage \\
\hline Monotherapy & $\mathbf{6 5}$ & $\mathbf{( 7 0 \% )}$ \\
- Phenytoin & 41 & $44 \%$ \\
- Valproic acid & 11 & $12 \%$ \\
- Clobazam & 4 & $4 \%$ \\
- Carbamazepine & 9 & $10 \%$ \\
Polytheraphy 2 AED & $\mathbf{2 3}$ & $\mathbf{( 2 4 \% )}$ \\
- Phenytoin + Clobazam & 6 & $6 \%$ \\
- Phenytoin + Carbamazepin & 8 & $9 \%$ \\
- Phenytoin + Valproic Acid & 5 & $5 \%$ \\
- Carbamazepin + Clobazam & 2 & $2 \%$ \\
- Valproic acid + & 2 & $2 \%$ \\
$\quad$ Carbamazepin & $\mathbf{5}$ & $\mathbf{( 6 \% )}$ \\
Polytheraphy 3 AED & & \\
- Valproic Acid + & Carbamazepine + & \\
$\quad$ Clobazam & & \\
- Phenytoin + Valproic acid & & \\
$\quad$ + Clobazam & 1 & $1 \%$ \\
- Phenytoin + Carbamazepin & & \\
$\quad$ + Clobazam & 2 & $2 \%$ \\
\hline
\end{tabular}

Of the overall AED prescribed, phenytoin is still the AED that is most often given to epilepsy patients as monotherapy. Then followed by giving valproate acid $(12 \%)$ and carbamazepine (10\%). Of 93 patients, 65 patients $(70 \%)$ received AED monotherapy. While the remaining $24 \%$ of patients get 2 AED and $6 \%$ of patients get more than 2 AED. For the most combinations of AED (8 patients) with phenytoin and carbamazepine (table 3 ).

From table 4 it can be concluded that, of the 93 epilepsy patients who controlled and filled the questionnaire, 40 patients said they experienced some side effects in the use of AED. $17,2 \%$ of patients (16 people) had gingival 
hypertrophy due to the use of one AED namely phenytoin. $7.53 \%$ ( 7 people) patients experience disorders of the liver (transaminitis), the use of phenytoin alone, as well as a combination of phenytoin and carbamazepine. 5\% of patients experience dizziness especially in the use of carbamazepine, weight gain in the use of valproic acid or phenytoin, and hair loss in the use of single phenytoin, or in combination. 1 patient has ataxia due to the use of phenytoin, and 1 other person experiences thrush due to carbamazepine. Whereas $56.99 \%$ of patients experienced no side effects during the use of AED. From the results of the chi square test (table 5), it was found that the side effects were not significantly significant in the use of monotherapy or polytherapy ( $\mathrm{p}$-value> 0.05).

Table 4. Side effects of AED based on the amount of AED prescribed

\begin{tabular}{lcccc}
\hline Side Effect & $\begin{array}{c}\text { Monotherapy } \\
(\%)\end{array}$ & $\begin{array}{c}\mathbf{2} \\
\text { drugs } \\
(\%)\end{array}$ & $\begin{array}{c}>2 \\
\text { drugs( } \\
\mathbf{\%})\end{array}$ & Total \\
\hline Side Effect & $30(46 \%)$ & 9 & 1 & 40 \\
$(+)$ & 1 & $(39 \%)$ & $(20 \%)$ & $(43,01 \%)$ \\
Oral ulcer & 1 & & & $1(1,07 \%)$ \\
Ataxia & 3 & 2 & & $1(1.07 \%)$ \\
Weight gain & 5 & 2 & & $5(5.38 \%)$ \\
Transaminitis & 3 & 1 & 1 & $5(5.33 \%)$ \\
Dizziness & 14 & 2 & & $16 \%)$ \\
Gingival & 3 & 2 & & $(17.20 \%)$ \\
Hypertrophy & $35(54 \%)$ & 14 & 4 & $5(5.38 \%)$ \\
Hair loss & $(61 \%)$ & $(80 \%)$ & $(56.99 \%)$ \\
Side Effect (-) & & & & 53 \\
\hline
\end{tabular}

Table 5. Relationship of AED side effects based on the amount of AED

\begin{tabular}{lcccc}
\cline { 2 - 5 } & Monotherapy & $\mathbf{2}$ & $>\mathbf{2}$ & p-value \\
\hline Side Effect (+) & 30 & 9 & 1 & 0 \\
Side Effect (-) & 35 & 14 & 4 & 0,476 \\
\hline
\end{tabular}

Table 6. Relationship of side effects with a duration of AED usage

\begin{tabular}{lccc}
\hline $\begin{array}{l}\text { Duration of AED } \\
\text { usage }\end{array}$ & Side Effect $(+)$ & Side Effect $(-)$ & p-value \\
\hline < 1 year & 6 & 7 & \\
$1-5$ years & 28 & 25 & $* 0,038$ \\
$6-10$ years & 4 & 7 & \\
$>10$ years & 2 & 14 & \\
\hline
\end{tabular}

The relationship between the duration of epilepsy, with the appearance of side effects, can be seen in table 6. 28 patients who experience side effects, appear after the duration of use of AED 1-5 years. Furthermore, at the duration of AED $<1$ year, side effects appeared in 6 patients. Whereas the least side effects appear on the duration of AED use> 10 years. From the effect test using chi square, it was found that the duration of AED usage influenced the emergence of side effects ( $p$-value $<0.05$ ).

\section{Discussion}

In terms of age, the largest population of epilepsy is at the age of 25-50 years. This is consistent with the previous theory, that in developing countries the prevalence of epilepsy is higher at ages 1-2 years than in the elderly (> 50 years). ${ }^{1}$ Whereas in developed countries, this applies vice versa. In a 2012 study, it was also said that in developing countries, the prevalence of epilepsy ranged in decades 3-4, and tended to decrease in the 5 decades. ${ }^{5}$
Based on sex, it was found that the prevalence of epilepsy was more in men, although not too significant $(55.9 \%)$. This is consistent with previous research that in Southeast Asia, the prevalence of men is slightly higher than that of women. ${ }^{1}$ Based on the form of seizure, it was found that $85 \%$ of study subjects had general forms of seizure. This is in line with previous studies in Africa, that on average in developing countries, the form of seizures in the form of general onset compared with focal onset. General seizures are said to be more frequent in the first 5 years, with the incidents going to be the same in both focal and general forms at the age of 6-24 years, and will be twice as frequent in adults $>24$ years. $^{5}$

The most common cause of epilepsy in this study was due to idiopathic causes (63 people). According to Lancet Neurology in 2019, where globally, idiopathic epilepsy ranks fifth in neurological disorders after stroke, migraine, dementia, and meningitis. Other studies in sub-Saharan Africa, idiopathic epilepsy ranks second out of all neurological abnormalities. ${ }^{6}$

The results also obtained that $>90 \%$ of sufferers do not have a family history of suffering from epilepsy. This is consistent with previous research, that most epilepsy sufferers do not have a family history, with the results of statistical tests that are not significant. This indicates that family history does not affect the onset of epilepsy. ${ }^{7}$

Viewed from the level of education, as many as $38.7 \%$ of patients have a high school education level, followed by the elementary school (28\%), junior high school (24.7\%), undergraduate $(5.4 \%)$, and out of school (3.2\%). This is consistent with research in India in 2015, that in urban areas, most people with epilepsy have a high school education level. However, looking at the incidence in the world, it is said that low socioeconomic status, low income, and low education are risk factors for epilepsy. This has a direct effect on hospitalization, uncontrolled seizures, and drug-related side effects. ${ }^{8}$

In this study, it was also found that the duration of epilepsy was $>5$ years $(>50 \%)$. The duration of epilepsy affects the overall quality of life of epilepsy sufferers. This was demonstrated through research in India in 2011, where there was a decrease in the quality of life score of epilepsy sufferers for a longer duration of epilepsy. ${ }^{9}$

In the case of epilepsy, the selection of anti-epileptic drugs plays an important role in determining the success of therapy. The ultimate goal of epilepsy therapy is seizurefree without side effects. This is because epilepsy patients are often faced with the problem of side effects of AED use, which often leads to failure of epilepsy therapy. ${ }^{1}$

In this study, it was found that $70 \%$ of patients received AED monotherapy. The most widely used AED is phenytoin (44\%), valproate acid (12\%), carbamazepine (10\%), and clobazam (4\%). This is consistent with the theory that monotherapy is the first choice for patients with epilepsy. ${ }^{1}$ In line with this study, it was reported that $82.2 \%$ of patients received monotherapy, this is also in line with research in Ethiopia that more than $70 \%$ of patients received monotherapy The main thing is the use of phenobarbital, followed by phenytoin. ${ }^{10}$

In the case of polytherapy, phenytoin is the most commonly prescribed AED in combination with other AED, both in 
the case of polytherapy 2 AED (phenytoin combined with clobazam, or carbamazepine, or valproate acid) or in the case of polytherapy 3 AED. Clobazam is the third additional AED, the most widely prescribed in this study, of which of 5 patients with 3 AED polytherapy, all three received additional AED in the form of clobazam. This is slightly different from research conducted in 2017, where valproic acid is most often prescribed as AED, followed by carbamazepine, phenytoin, and levetiracetam. While carbamazepine, AED is the most widely combined with> 2 AED. $^{2}$

Besides seizure control and optimizing the quality of life of patients, one of the main goals of epilepsy treatment is to reduce the side effects caused by AED treatment. Of the 93 study subjects, 40 patients experienced side effects (43\%). The 40 patients experienced at least one dominant side effect. The most side effects are gingival hypertrophy $(16 \%)$ due to the use of phenytoin. Other side effects in the form of impaired liver function/transaminitis (7.53\%), weight gain, dizziness, and hair loss were experienced by 5 patients $(5.38 \%)$ respectively. There was 1 patient $(1.07 \%)$ who had thrush, and there was also 1 patient who had ataxia in using phenytoin. This is different from a study in New York in 2019, where it was said that fatigue and memory disorders were the most common side effects of research subjects. ${ }^{11}$

Another cross-sectional study of 354 adult epilepsy patients with a sample of patients with antiepileptic drugs for at least 1 year, and cooperative. Of all samples, $86.2 \%$ of the types were GTC, with 79 side effects reported. The most common side effects were fatigue $(5.08 \%)$, GIT disorders $(4.24 \%)$, and sedation/depression (4.24\%). The most common side effects occur in patients with low education, polytherapy, and frequent seizure frequency (1-5 seizures/year). ${ }^{10}$

Based on the amount of AED given, it was found that side effects appeared in $46 \%$ of patients given monotherapy therapy, while there were $9(39 \%)$ patients with polytherapy 2 AED who experienced side effects. Furthermore, there were 1 (20\%) patients with polytherapy 3 AED who experienced side effects. This is different from previous cohort studies, concluded that in $50 \%$ of patients treated with polytherapy, $83 \%$ experienced two or more side effects. ${ }^{11}$

The discrepancy in the results of this study could have been influenced by the number of samples, the type of AED used, and the type of epilepsy that appeared in many studies. In this study, more than $80 \%$ of patients received monotherapy, so the side effects that appeared most likely also from patients who received monotherapy.

Factors influencing the side effects of AED in epilepsy patients were also investigated in India in 2017. A multivariate study was conducted, which took into account age, sex, seizure onset, and seizure type, on the emergence of side effects. It said there was no correlation between the factors mentioned above to the emergence of side effects. But it is said the number and duration of AED administration significantly influence the incidence of side effects. ${ }^{2}$ In line with this study, in this study, it was found that there was no significant effect between the type and duration of epilepsy on the emergence of side effects (pvalue>0.05).

The combination of AED in epilepsy therapy is indeed needed, where the relationship between increased side effects, will cause restrictions on polytherapy. However, the chi square test results in this study found that the side effects did not differ significantly both in the use of monotherapy and polytherapy $(p>0.05)$. This might be due to the minimum sample size and different populations. It was also said in a 2010 study that high doses of AED (independent of mono or polytherapy) would increase the number of controlled seizures, but would increase the incidence of side effects. So the reduction in dosage is needed to minimize side effects. ${ }^{12}$

On the other hand, in the chi square test on the duration of AED use (table 5.6) on the appearance of side effects, it was found that there was a significant relationship between the duration of AED use and the incidence of side effects (p-value $<0.05$ ). This is consistent with research in India in $2017 .^{2}$

The results of this study must certainly be interpreted with due regard to some limitations. The main limitations of this study are, not too much sample and subjective reporting. These side effects that are reported subjectively should be followed by objective examinations such as laboratory tests and other diagnostic tools. This type of cross-sectional study also cannot describe the causal relationship between AED and the side effects that arise.

\section{Conclusion}

There are at least $40 \%$ of patients taking AED experiencing side effects. Gingival hypertrophy is the most common side effect of patients complaining when using phenytoin. Side effects that appear in this study are thought to be related to several factors, which when tested for significance were the duration of AED use. This basic data can be used to increase the awareness of clinicians related to the emergence of side effects in patients who consume AED. But of course, this research still requires a larger scale cohort of data, using standard instruments, because often the use of questionnaires alone, will cause overestimation of cases of side effects, thus creating bias.

\section{Conflict of Interest}

None of the authors has any conflict of interest to disclose

\section{Acknowledgement}

The researchers would like to thank to Brawijaya University and Dr. Saiful Anwar General Hospital, Malang, East Java, Indonesia for facilitating this research.

\section{References}

1. Kusumastuti, K., Gunadharma, S. and Kustiowati, E. Pedoman Tatalaksana Epilepsi, Pusat Penerbitan dan Percetakan Unair. 2017.

2. Joshi R, Tripathi M, Gupta P, Gulati. Adverse effects and drug load of antiepileptic drugs in patients with 
epilepsy: Monotherapy versus polytherapy. Indian J Med Res; 2017. 145:317-326.

DOI: 10.4103/ijmr.IJMR_710_15

3. GA Baker, A Jacoby, D Buck, C Stalgis, and D Monnet. Quality of life of people with epilepsy: A European study. Epilepsia; 1997. 38(3):353-362. DOI: $10.1111 / \mathrm{j} .1528-1157.1997 . t b 01128 . x$

4. Cramer JA, Mintzer S, Wheless J, \& Mattson RH. Adverse effects of antiepileptic drugs: A brief overview of important issues. Expert Review of Neurotherapeutics; 2007. 10(6):885-891. DOI: 10.1586/ern.10.71

5. Banerjee N, Filippi D. and Hausser A. The descriptive epidemiology of epilepsy : A review. Epilepsy Res; 2009. 85(1):31-45.

DOI: $10.1016 /$ j.eplepsyres.2009.03.003

6. Lancet N. Global, regional, and national burden of epilepsy, 1990 - 2016: A systematic analysis for the global burden of disease study. Lancet Neurol; 2019. DOI: $10.1016 / \mathrm{S} 1474-4422(18) 30454-\mathrm{X}$

7. Canpolat M. et al. Prevalence and risk factors of epilepsy among school children in Kayseri City Center, An urban area in Central Anatolia, Turkey.
Seizure: European Journal of Epilepsy. BEA Trading Ltd; 2014. 23(9):708-716.

DOI: 10.1016/j.seizure.2014.05.012.

8. Amudhan S, Gururaj G, Satishchdanra P. Epilepsy in India I: Epidemiology dan public health. Ann Indian Acad Neurol; 2015. 18:268-77. Available from: http://www.annalsofian.org/text.asp?2015/18/3/263/16 0093

9. Shetty PH. et al. Quality of life in patients with epilepsy in India. J Neurosci Rural Pract; 2011. 2(1):33-40. DOI: 10.4103/0976-3147.80092

10. Ayalew MB. Patient reported adverse events among epileptic patients taking antiepileptic drugs. SAGE Open Med; 2018. DOI: 10.1177/2050312118772471

11. Perucca P, Carter J, Vahle V. Adverse Antiepileptic Drug Effects. Epilepsy Currents; 2010. 10(1):11-12. DOI: $10.1111 / \mathrm{j} .1535-7511.2009 .01339 . x$

12. Goldenberg MM. Overview of drugs used for epilepsy and seizures etiology, diagnosis, and treatment; 2010. 35(7). Available from:

https://www.ncbi.nlm.nih.gov/pmc/articles/PMC2912 003/ 